\title{
THE USE OF A BERYLLIUM HOPKINSON BAR TO CHARACTERIZE A PIEZORESISTIVE ACCELEROMETER IN SHOCK ENVIRONMENTS*
}

\author{
Vesta I. Bateman \\ Fred A. Brown \\ Neil T. Davie \\ Sandia National Laboratories \\ Albuquerque, New Mexico 87185
}

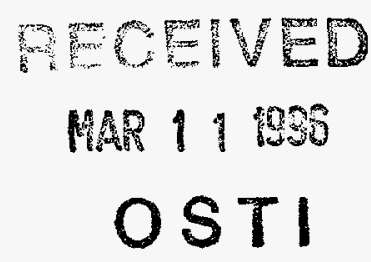

\section{Authors' Biographies}

Vesta I. Bateman received a B.S. degree from Vanderbilt University and a M.S. and Ph.D. from the University of Arizona, all in Mechanical Engineering. She taught for four years in the Mechanical Engineering Department at Virginia Tech. Since 1980, she has been at Sandia National Laboratories in Albuquerque, New Mexico where she is a Senior Member of the Technical Staff in the Mechanical Shock Testing Laboratory.

Neil T. Davie received a B. A. degree in math and physics from Augustana College in 1976. He received a M. S. degree in Theoretical and Applied Mechanics from the University of Illinois. Since that time, he has been employed by Sandia National Laboratories. He was involved in mechanical modeling and structural analysis until 1982 when he began working in the area of shock testing and pyroshock simulation. Presently, he is a Senior Member of the Technical Staff in the Shock Testing Laboratory.

Fred A. Brown has over twenty years of shock testing experience in the Mechanical Shock Laboratory at Sandia National Laboratories. $\mathrm{He}$ has participated in the development of many different types of shock-producing mechanisms including resonant fixturing for pyroshock simulation, Hopkinson bar testing for component evaluation, and innovative drop table configurations for specialized shock requirements.

\section{Abstract}

The characteristics of a piezoresistive accelerometer in shock environments are being studied at Sandia National Laboratories in the Mechanical Shock Testing Laboratory. A Hopkinson bar capability has been developed to extend our understanding of the piezoresistive accelerometer, in two mechanical configu-

\footnotetext{
* This work was supported by the U.S. Department of Energy under DE-AC04-94AL85000.

1996

PROCEEDINGS-Institute of Environmental Sciences
}

rations, in the high frequency, high shock environments where measurements are being made. In this paper, the beryllium Hopkinson bar configuration with a laser doppler vibrometer as the reference measurement is described. The in-axis performance of the piezoresistive accelerometer for frequencies of $\mathrm{dc}-50 \mathrm{kHz}$ and shock magnitudes of up to $70,000 \mathrm{~g}$ as determined from measurements with a beryllium Hopkinson bar are presented. Preliminary results of characterizations of the accelerometers subjected to cross-axis shocks in a split beryllium Hopkinson bar configuration are presented.

\section{Keywords}

Accelerometer, high shock, high acceleration, high frequency, Hopkinson bar, beryllium Hopkinson bar, cross-axis sensitivity.

\section{Introduction}

Sandia National Laboratories (SNL) conduct impact testing for a variety of structures. These impact tests include earth and rock penetrator tests in which a penetrator structure is propelled at velocities of $1000 \mathrm{fps}$ (nominal) into earth or rock. During an impact test, metal to metal contact may occur within the structure and produce high frequency, high amplitude shocks. The piezoresistive accelerometer, which is frequently used for field tests of various high reliability structures, must withstand these severe shock environments. The piezoresistive accelerometer has several desirable characteristics: dc response, low power requirements, minimal zero shift, and high resonant frequency. A bandwidth of at least $10 \mathrm{kHz}$ is needed for many applications because more sophisticated analyses are being performed with the field data. Additionally, requirements are being made to qualify components for frequency ranges of $10 \mathrm{kHz}$. For example, recent Army research has found that armored vehicle components can be damaged by the high frequency content of ballistic shock $[1,2,3]$. To enhance survivability of the new generation of combat vehicles, the Army has specified a minimum frequency range of $10 \mathrm{kHz}$ for the design and 


\section{DISCLAMMER}

Portions of this document may be illegible in electronic image products. Images are produced from the best available original document. 
qualification test of components. Qualification to even higher frequencies is desired, if reasonably possible.

Higher frequency measurements (in excess of $10 \mathrm{kHz}$ ) at acceleration levels in excess of $20,000 \mathrm{~g}$ are being attempted. Recent applications of piezoresistive accelerometers include pyroshock measurements such as stage separation shock for multistage missile programs (for example, STARS, Strategic TARget System, program) and the USS IOWA explosive accident simulation. Impact and pyroshock phenomena contain high frequencies (up to $100 \mathrm{kHz}$ ), and there is no capability to calibrate or characterize accelerometers with shock inputs for frequencies above $10 \mathrm{kHz}$. Additionally, recent penetrator testing by SNL has used data packages with bandwidths of dc- $60 \mathrm{kHz}$ for onboard recording of accelerometer response in excess of $35,000 \mathrm{~g}$ during penetration events. These accelerometer measurements are made with the piezoresistive accelerometers mounted inside a data package with no mechanical isolation other than the data package itself. The piezoresistive accelerometers are being characterized over the extended bandwidth of dc to $50 \mathrm{kHz}$ to provide better interpretation of these high frequency measurements. To achieve this goal, a beryllium Hopkinson bar has been developed to extend the upper limit of the frequency range for Hopkinson bar calibration and characterization of accelerometers. The reference measurement for the beryllium Hopkinson bar is a commercial laser doppler vibrometer (LDV) that has been certified by the SNL Primary Electrical Standards Laboratory [4].

Others have been successful in extending the frequency range of the Hopkinson bar by removing dispersion effects from the data $[5,6]$. However, our goal is to achieve the additional frequency bandwidth without additional processing of the data. A beryllium Hopkinson bar will allow measurement of frequencies in the bandwidth of DC to $50 \mathrm{kHz}$ because of the beryllium's high stress wave speed that allows a shorter pulse duration than other Hopkinson bar materials that are used for the current accelerometer studies.

Current calibration of accelerometers is conducted for a maximum of $15,000 \mathrm{~g}$. In the applications listed above, the piezoresistive accelerometer is being used to measure accelerations in excess of $15,000 \mathrm{~g}$. In some cases, a $200,000 \mathrm{~g}$ accelerometer is being used. The SNL Mechanical Shock Laboratory has a titanium Hopkinson bar capability to test accelerometers up to $200,000 \mathrm{~g}$ that has been used to determine the characteristics of a piezoresistive accelerometer at these high acceleration levels [7]. The SNL titanium Hopkinson bar with strain gages as the reference measurement has been calibrated for a bandwidth of dc to $10 \mathrm{kHz}$ with an uncertainty of + $6 \%$ [8]. The reference measurement for the beryllium Hopkinson bar is the LDV which has been certified with an uncertainty of $\pm 5 \%$. The two areas of high frequency performance and high shock (acceleration level) performance for the piezoresistive accelerometer, in the two mechanical configurations shown below, are being pursued because measurements are being made in these environments.

\section{Accelerometer Mechanical Configurations}

There are two mechanical configurations for the piezoresistive accelerometer as shown in Figure 1. The rectangular package that uses two \#4-40 screws for mounting will be referred to as the flat package in this
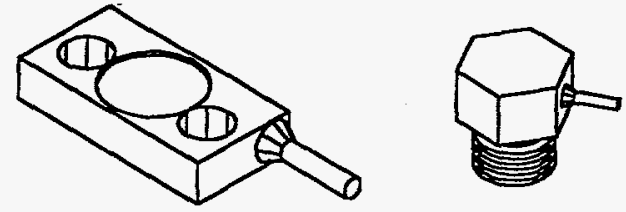

$$
\begin{array}{ll}
\text { Accelerometer, } & \text { Accelerometer, } \\
\text { Flat Configuration } & \text { Can Configuration }
\end{array}
$$

Figure 1: Two Mechanical Configurations for a Piezoresistive Accelerometer.

paper. The cylindrical package that uses a single \#1/4-28 mounting stud will be referred to as the can package. Both configurations are being studied to determine if there are any differences in the performance characteristics between the two accelerometers. In some cases, it has been suspected that the flat package exhibited beam mode (with fixed end conditions) response in high frequency environments. It has been hypothesized that the can package might eliminate this beam response and the subsequent frequency content in the measured accelerometer response data.

\section{Hopkinson Bar Configurations}

The beryllium Hopkinson bar configuration for characterizing accelerometers for normal or in-axis input is shown in Figure 2. Normal input in this configuration is an input that is normal to the mounting surface and is also parallel to the integral mounting stud. A maximum shock magnitude of $70,000 \mathrm{~g}$ is used for the beryllium bar to insure that the beryllium will not yield and cannot cause a health hazard. Both of the mechanical configurations for the piezoresistive accelerometer have been tested with the normal input. The reference 
measurement is the LDV as shown. Strain gages cannot be used as the reference measurement because the beryllium bar's response exhibits two anomalies that have been presented previously [4]: the high rate of damping and the non-return to zero of the stress. A configuration that uses a quartz crystal to directly measure the acceleration applied to an accelerometer mounted on a flyaway device at the end of the bar was investigated [9]. However, it was found that the Hopkinson bar material is limited to aluminum that matches the impedance of the quartz crystal.

Cross-axis sensitivity of the piezoresistive accelerometers is being studied with the Hopkinson bar configurations shown in Figures 3 and 4. An in-axis response is the response of an accelerometer whose sensitive axis is in the direction of the shock. An out-of-axis or cross-axis response is the response of an accelerometer whose sensitive axis is not in the direction of the shock and is obtained with the configurations in Figures 3 and 4 . The $90^{\circ}$ cross-axis configuration proposed previously [4] was abandoned because the end-modes at $120 \mathrm{kHz}$ in the Hopkinson bar caused the accelerometers to resonate and break. Both time domain calculations, as a percent difference from the reference LDV measurement, and frequency domain calculations, as frequency response functions, are made with the Hopkinson bar data.

\section{Hopkinson Bar Analysis}

The theory of stress wave propagation in a Hopkinson bar is well documented in the literature $[10,11]$. The results of this theory are summarized as follows:

A Hopkinson bar is defined as a perfectly elastic, homogeneous bar of constant cross-section.

A stress wave will propagate in a Hopkinson bar as a onedimensional elastic wave without attenuation or distortion if the wavelength, $\lambda$, is large relative to the diameter, $D$, or $10 \mathrm{D} \leq \lambda$.

For a one-dimensional stress wave propagating in a Hopkinson bar, the motion of a free end of the bar as a result of this wave is:

$$
v=2 c \varepsilon
$$

or,

$$
a=2 c \frac{d \varepsilon}{d t}
$$

where,

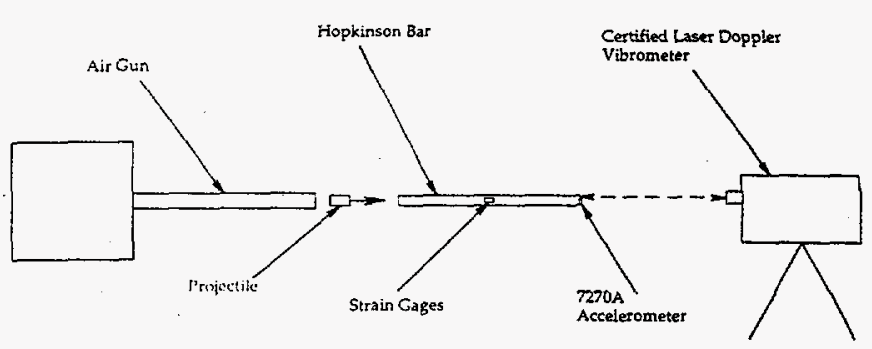

Figure 2: Beryllium Hopkinson Bar Configuration for Normal Input.

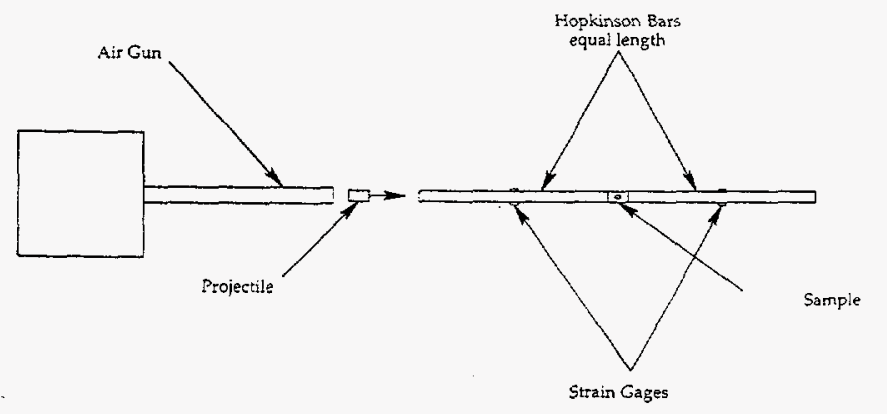

Figure 3: Split Beryllium Hopkinson Bar Configuration for Cross-Axis Input.

Beryllium Flat Package Insert Beryllium Can Package Insert
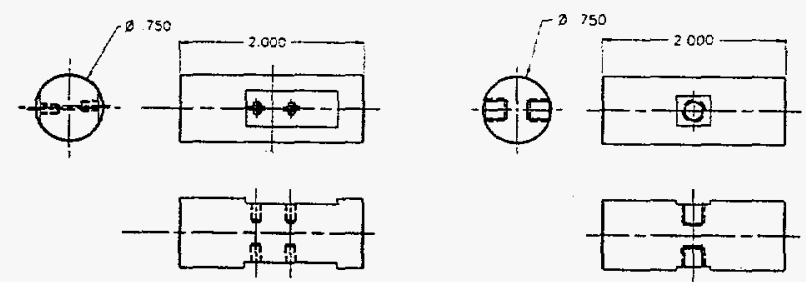

Figure 4: Sample Configuration for Split Beryllium Hopkinson Bar for Cross-Axis Input.

$$
c=\sqrt{\frac{E}{\rho}}
$$

and $v$ and $a$ are the velocity and acceleration, respectively, of the end of the bar, $c$ is the wave propagation speed in the bar, $E$ is the modulus of elasticity, $\rho$ is the density for the Hopkinson bar material, and $\varepsilon$ is the strain measured in the bar at a location that is not affected by reflections during the measurement interval.

The motion of an accelerometer mounted on the end of the bar will be governed by equations (1) and (2) if the mechanical impedance of the accelerometer is much less than that of the bar or if the thickness of the accelerometer is much less than the wavelength. The requirement on the strain gage is that the gage length (g.l.) be much less than the wavelength or $\lambda \geq 10$ g.l. 
The Shock Laboratory beryllium Hopkinson bar for accelerometer testing is made of beryllium ( $99 \%$ pure) with a 0.76 inch diameter and a 50 in. length. The bar is supported in a way that allows it to move freely in the axial direction. A low pressure air gun is used to fire a 2 inch long hardened tool steel projectile at the end of the bar. This impact creates a stress pulse which propagates toward the opposite end of the Hopkinson bar. The amplitude of the pulse is controlled by regulating the air gun pressure, which determines the impact speed. The shape (approximately a half sine) and duration of the pulse are controlled by placing various thickness of paper ( $3 \times 5$ index cards) on the impact surface. The LDV is located at the end of the bar on which the accelerometer is mounted and measures velocity at a point next to the accelerometer.

Once recorded, the velocity (LDV) and acceleration (accelerometer) records can be compared by converting to either velocity or acceleration as shown in (1) and (2). Hopkinson bar accelerometer calibration methods documented in the literature [12-15] generally use velocity, in which case the accelerometer record is integrated and compared directly to the strain record converted to velocity by the factor $2 \mathrm{c}$. This provides smooth curves for comparison of time histories, however much of the higher frequency information is lost due to the integration process. Since it was desired to preserve the frequency response of the data, acceleration is used for the comparison of the data. Consequently, the time derivative of the strain records was required, and the resulting signal may be contaminated by high frequency noise created in the process of calculating the derivative. This problem was essentially eliminated by: 1) adequate sample rate of $500 \mathrm{kHz}$ or higher; 2) low pass digital filtering with a cutoff frequency well above the frequency range of interest $(10 \mathrm{kHz})$; and most importantly, 3) an accurate differentiation algorithm which was derived using the Fourier series reconstruction techniques in [15]. This algorithm results in an exact derivative of the digitized signal providing the Sampling Theorem has not been violated, that is, the data is not aliased [16].

\section{Laser Doppler Vibrometer Certification Results}

A LDV with high frequency (up to $1.5 \mathrm{MHz}$ ) and high velocity $(10 \mathrm{~m} / \mathrm{s})$ capability was purchased from a commercial source and has been certified by the Primary Electrical Standards Department at SNL. The certification process consisted of using a calibrated arbitrary waveform generator (AWG) to create frequency modulated (FM) signals that were input to the detector in the LDV with a laser diode. The frequency modulated signals simulated short duration haversine pulses with various repetition rates, a rise time measurement using ramped signals, a bandwidth measurement with sinusoidally varying velocity, and a verification of the slew rate specification using small signals up to 1.5 $\mathrm{MHz}$. The main contributors to the uncertainty of the LDV are: 1) the frequency of the FM signal generated by the Tektronix Model AWG 2040 arbitrary waveform generator; (2) the uncertainty of the voltage measurements with the Tektronix Model 11402 or Model DSA $602 \mathrm{~A}$ digitizing waveform recorder with a Model 11 A34 amplifier; (3) the residuals of a linear fit of the mean output velocity voltage to the theoretical output velocity voltage computed from the frequency of the modulating signal in the AWG 2040; and (4) the difference between the theoretical output voltage and the worst deviation from the theoretical output voltage. The total uncertainty for a particular velocity is the square root of the sum of the squares (RSS) of the values from sources 1 to 3 plus the value of source 4 The random components (1) to (3) are combined as RSS. Component (4) is a worst case error which is not combined as RSS. For the $1000 \mathrm{~mm} / \mathrm{s} / \mathrm{V}$ range (positive velocity), the total uncertainty with approximately a $95 \%$ confidence level for the velocity is $5 \%$. When the LDV is used over $90 \%$ of its range, this LDV has a $2-3 \%$ uncertainty for all specified frequencies and velocities. The uncertainty decreases for decreasing velocity scales. The LDV provides a reference velocity measurement for velocities up to $10 \mathrm{~m} / \mathrm{s}$ and for frequencies up to $1.5 \mathrm{MHz}$. This reference measurement provides information in a bandwidth that is not available from strain gages that are generally considered to have a bandwidth of no greater than DC- $40 \mathrm{kHz}$. The details of the certification process are described in [7].

\section{Piezoresistive Accelerometer Performance as Measured with the Beryllium Hopkinson Bar}

Each mechanical configuration for the accelerometer was mounted directly to the end of a Hopkinson bar and subjected to shock pulses of about $40,000 \mathrm{~g}$ and $70,000 \mathrm{~g}$ with nominal pulse durations of about $15-20 \mu \mathrm{s}$ in all cases. The magnitude of the accelerometer responses was compared to the acceleration magnitude derived from the LDV measurements. The results of these tests are summarized in Table 1. The percent deviations vary from $2 \%$ to $7 \%$ and no significant difference was observed in the two packages. Time history data for the two packages are shown in Figure 5. Fourier transforms are shown in Figure 6 and indicate that there is a resonance above 100 $\mathrm{kHz}$ for the can package that is not evident in the flat package. This resonance has been confirmed elsewhere 
TABLE 1

ACCELERATION COMPARISON FOR TWO ACCELEROMETER CONFIGURATIONS

$\begin{array}{ccc}\text { Accelerometer } & \underline{\mathbf{4 0 , 0 0 0}} \mathbf{g} & \mathbf{7 0 , 0 0 0 g} \\ \text { Can Package (1/4-28) } & 3 \% & 2 \% \\ \text { Flat Package (4-40) } & 4 \% & 7 \%\end{array}$

in unpublished results. These results are similar to those obtained for the titanium Hopkinson bar [4] and confirm the integrity of the beryllium Hopkinson bar configuration.

Next, frequency response functions (frf's) were calculated for both accelerometer configurations for the shock levels of $40,000 \mathrm{~g}$ and $70,000 \mathrm{~g}$ with a nominal duration of 15 to $20 \mu \mathrm{s}$. The process of calculating these functions has been described previously [6] and requires five consistent shocks at each level. The consistency of the time-domain

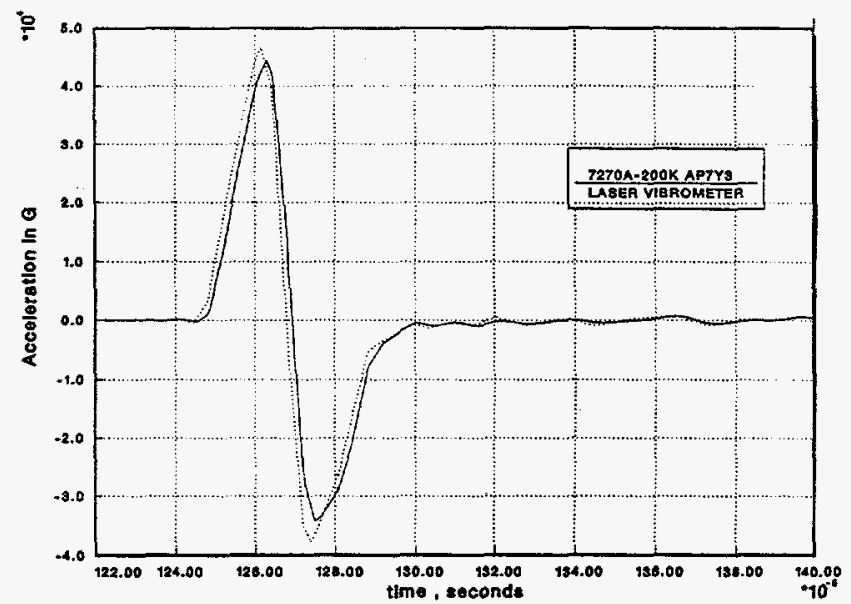

a) Flat Package

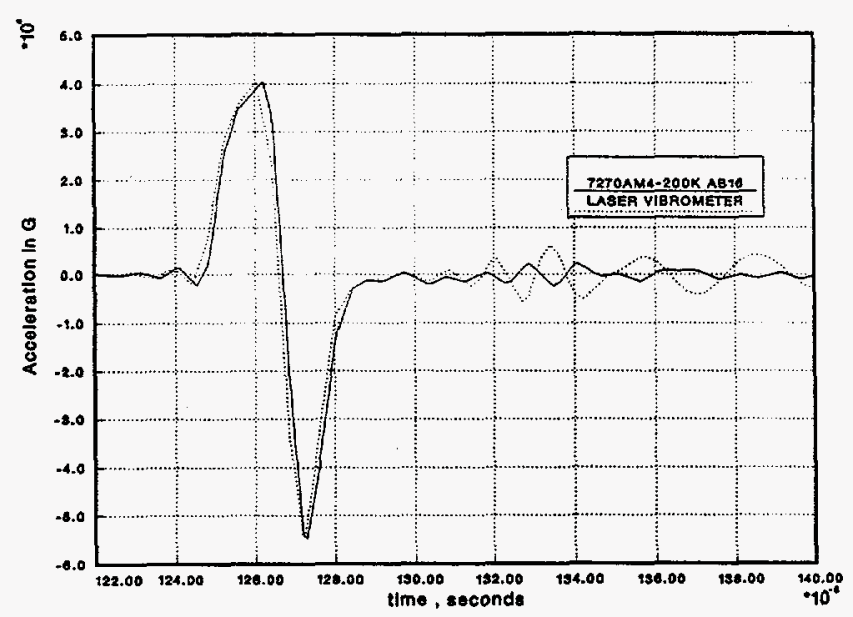

b) Can Package

Figure 5: Time History Data for Two Accelerometer Configurations at $40,000 \mathrm{~g}$.

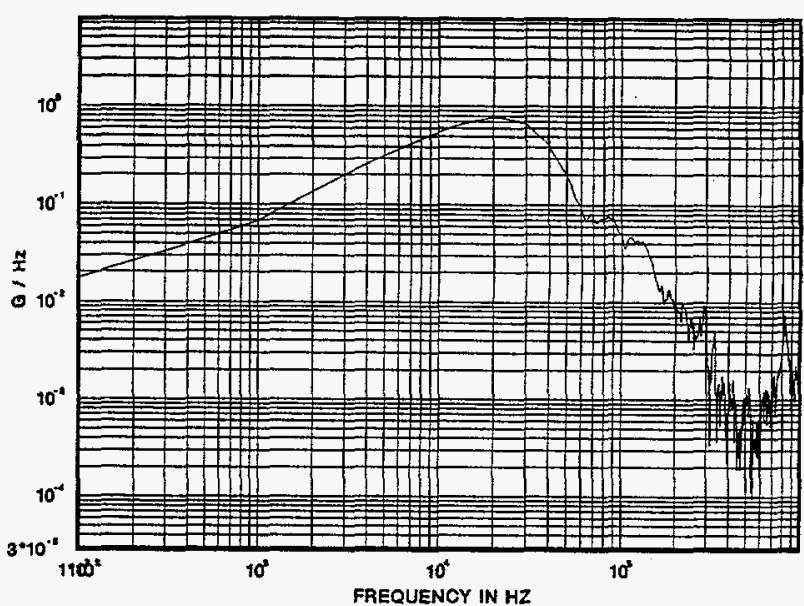

a) Flat Package

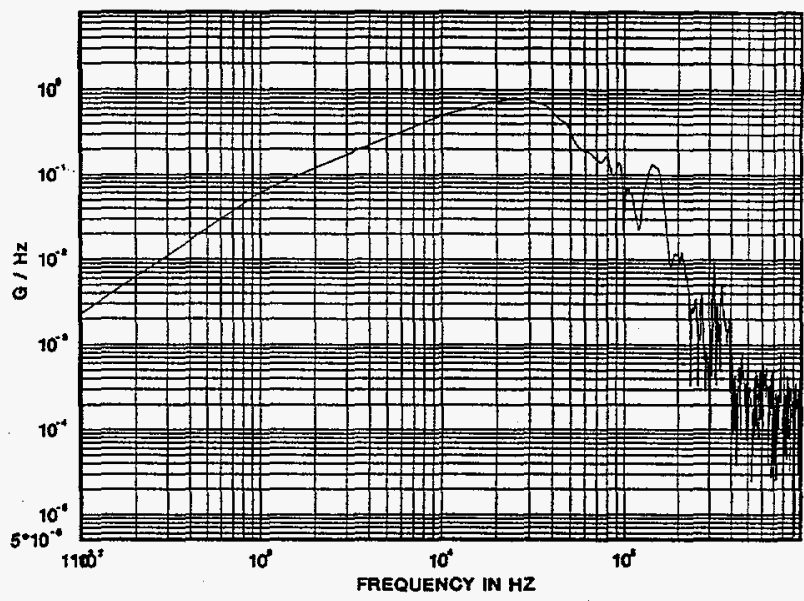

b) Can Package

Figure 6: Fourier Transforms for Two Accelerometer Configurations at $40,000 \mathrm{~g}$.

data required for the frf calculation is demonstrated in Figure 7. The frf's for the two accelerometer

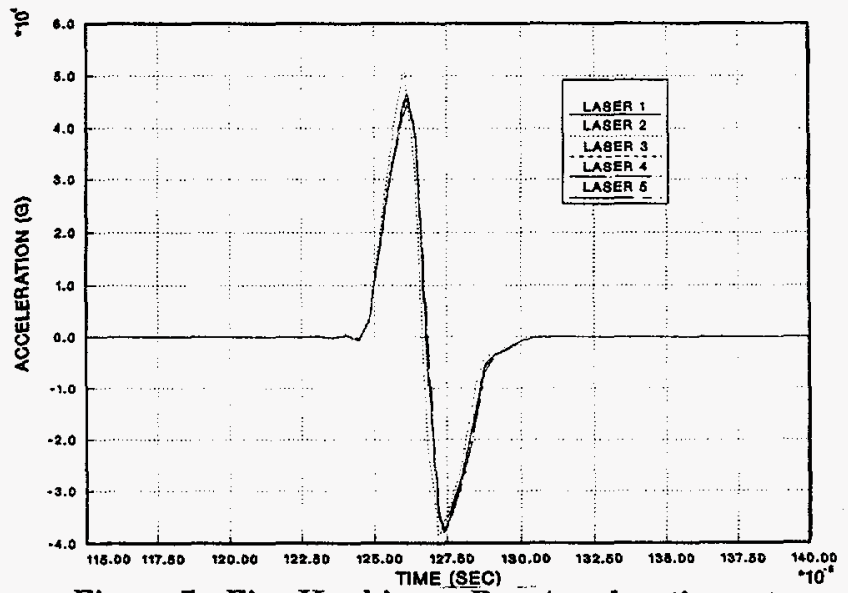

Figure 7: Five Hopkinson Bar Accelerations at $40,000 \mathrm{~g}$. 


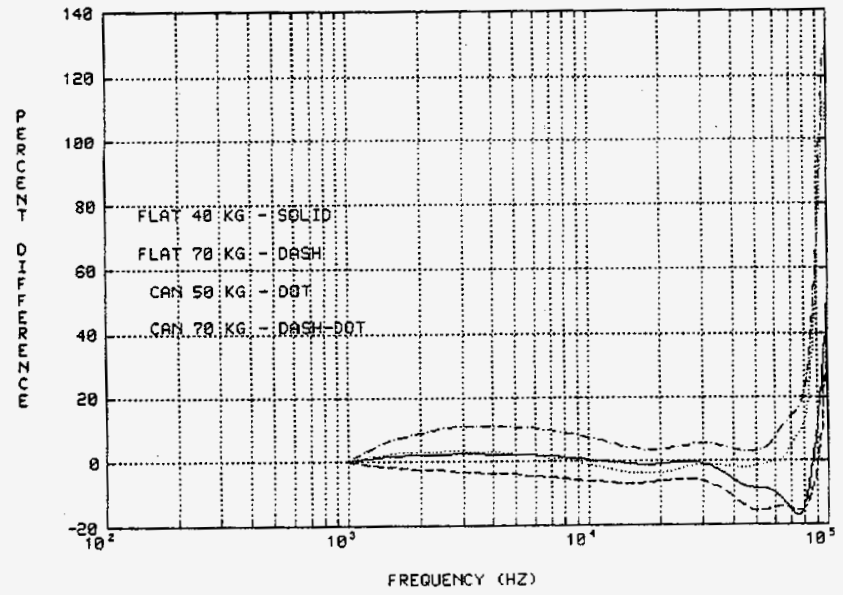

a) Magnitude

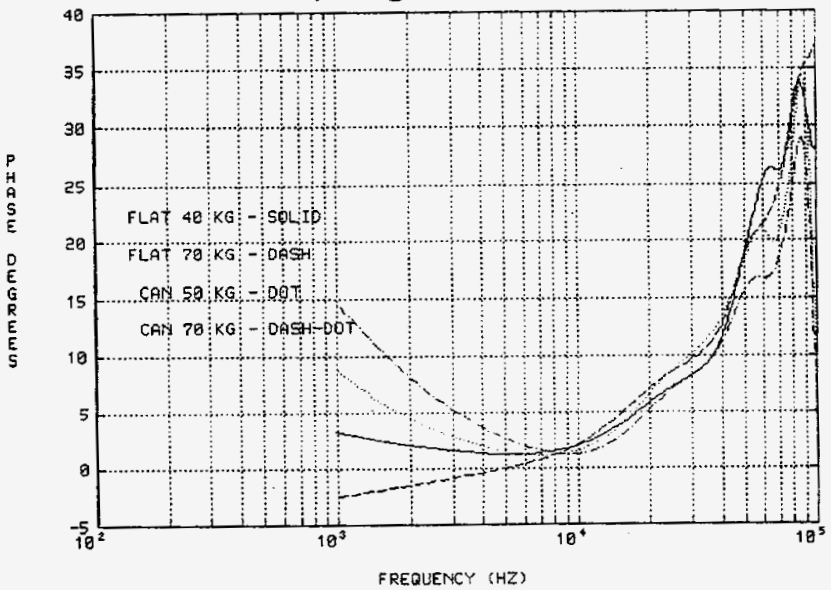

b) Phase

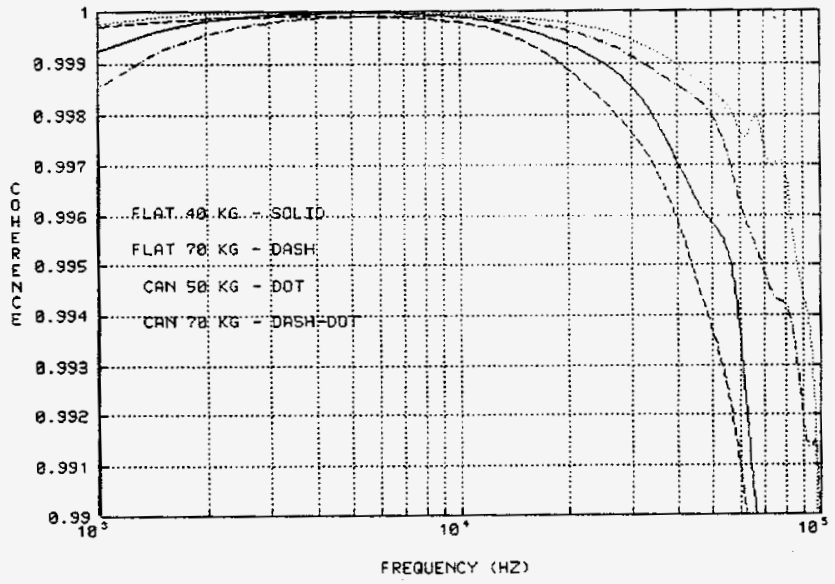

c) Coherence

Figure 8: Frequency Response Functions for Both the Flat and Can Packages.

configurations are shown in Figure 8. The fif's indicate that the two accelerometer configurations perform within the manufacturer's specifications at these levels and for these frequencies. The coherence shows that the frf calculations can be used up to a frequency of about 50 $\mathrm{kHz}$. Above $50 \mathrm{kHz}$, the lack of coherence creates an apparent resonance above $50 \mathrm{kHz}$ that is not a mechanical resonance in the accelerometer but an artifact of the frf calculation that is a function of the pulse duration [6].

\section{Cross-Axis Piezoresistive Accelerometer Performance as Measured with the Beryllium Hopkinson Bar}

The axial motion, a, at a location in the Hopkinson bar other than the free end is

$$
a=c \frac{d \varepsilon}{d t}
$$

where $\varepsilon$ is the axial strain. The radial motion, $y$, is

$$
y=r \varepsilon r
$$

where $r$ is the radius of the Hopkinson bar and $\varepsilon_{\mathrm{r}}$ is the radial strain. Since the relationship between axial and radial strain is

$$
\varepsilon_{r}=\mu \varepsilon
$$

where $\mu$ is Poisson's ratio, then the final expression for radial acceleration, $a_{y}$, is

$$
a_{y}=\frac{\mu r}{c} \frac{d a}{d t} .
$$

A prediction of the axial and radial acceleration for the beryllium Hopkinson bar using the equations above is shown in Figure 9. Strain measurements co-located with the accelerometers for the flat package insert of Fig. 4 in the split Hopkinson bar configuration are shown in Figures 10 and 11 and indicate a Poisson's ratio of about

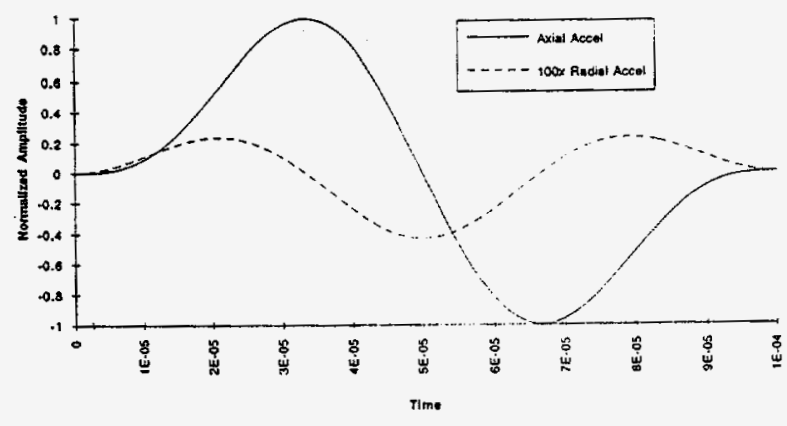

Figure 9: Theoretical Prediction of Axial and Lateral Accelerations for the Beryllium Hopkinson Bar. 


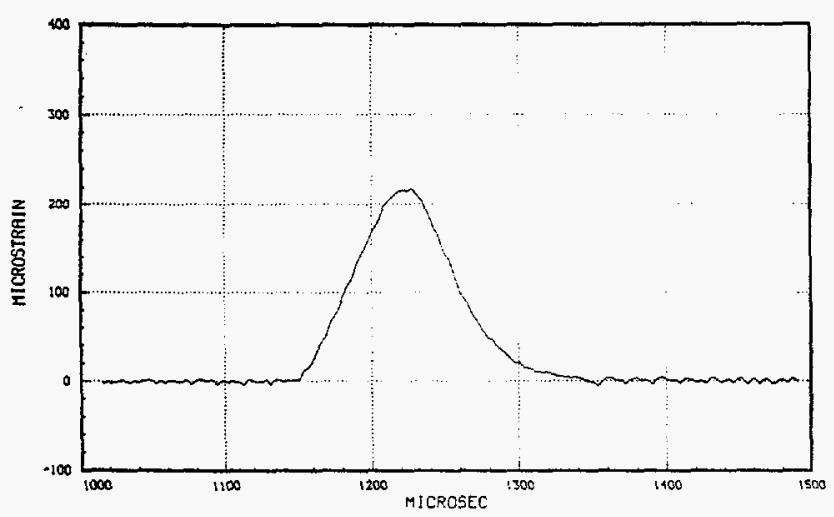

Figure 10: Axial Strain on the Beryllium Insert.

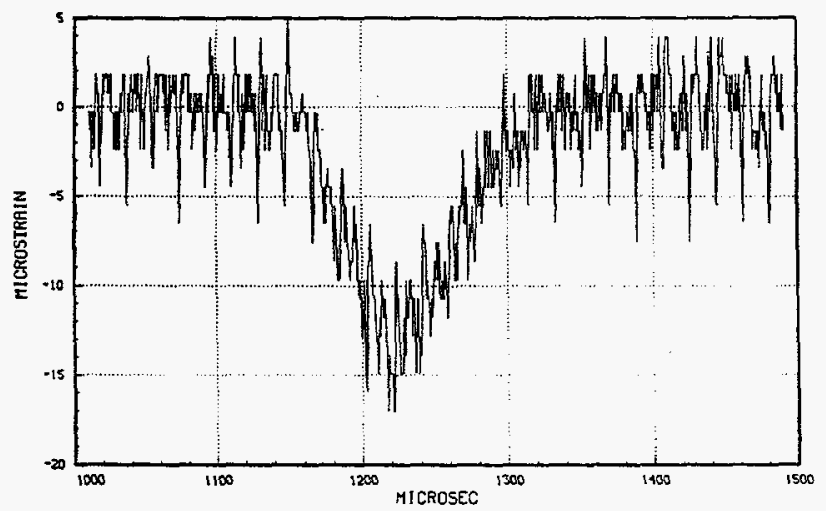

Figure 11: Lateral Strain on the Beryllium Insert.

0.07. Two accelerometer responses measured on the insert are shown in Fig. 12. This response is base strain dominated because it does not correspond to either of the curves in Fig. 9 but follows the general shape of the lateral strain response in Fig. 11. A compressive static load was applied to the insert with the results shown in Figs. 13 and 14. Since the sensitivity of the

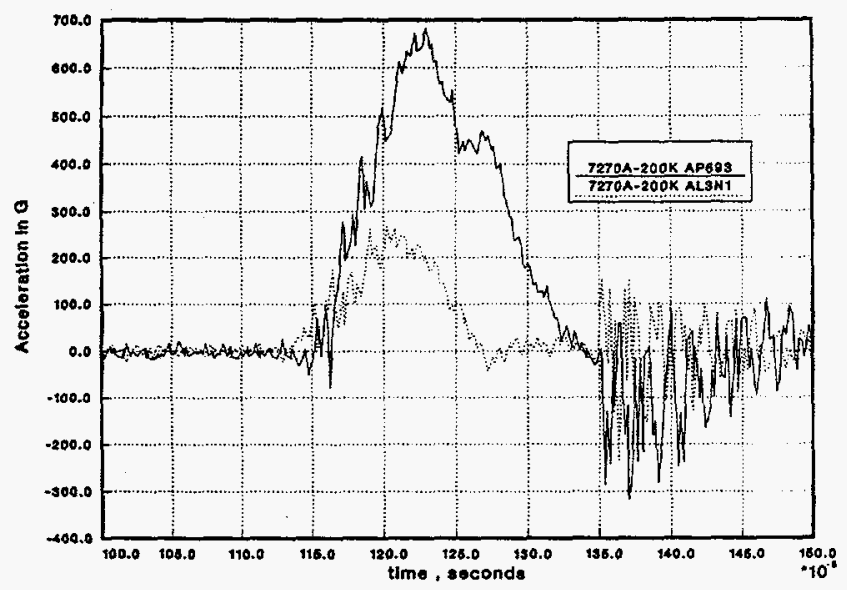

Figure 12: Two Accelerometer Responses Measured on the Beryllium Insert.

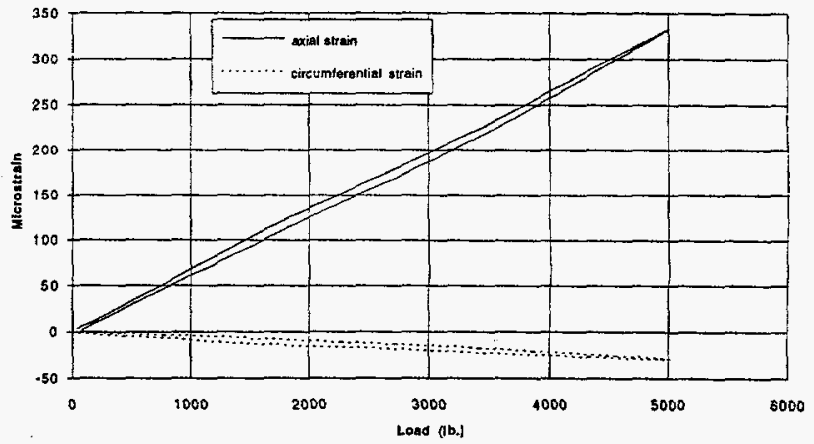

Figure 13: Strain Response for a Compressive Test of the Beryllium Insert.

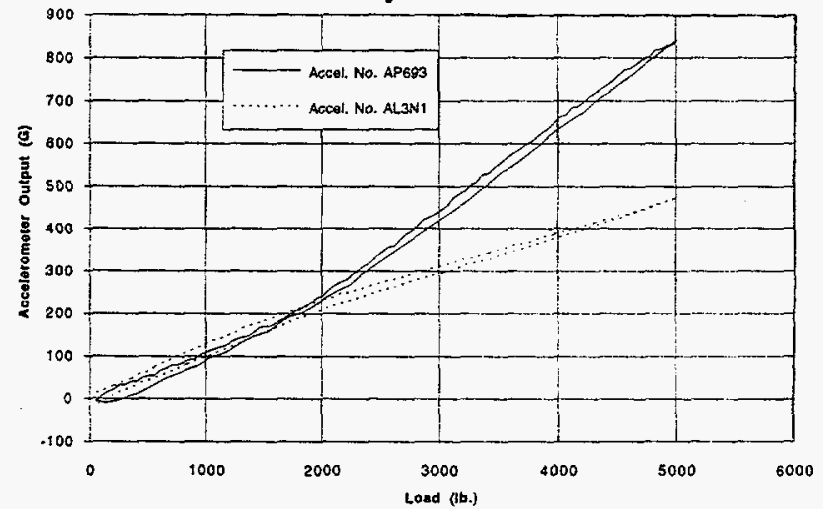

Figure 14: Accelerometer Response for a Compressive Test of the Insert.

accelerometer is approximately $1 \mu \mathrm{V} / \mathrm{g}$ and the applied strain was about $250 \mu \varepsilon$, these results are consistent with the manufacturer's specifications of $<0.5 \mathrm{mv}$ output for a strain of $250 \mu \varepsilon$.

\section{Conclusions and Future Work}

Two configurations of a piezoresistive accelerometer have been characterized over a bandwidth of DC to 50 $\mathrm{kHz}$ with a beryllium Hopkinson bar up to $70,000 \mathrm{~g}$. The reference measurement is a LDV that has been certified with an uncertainty of $\pm 5 \%$. The results shown in this paper for these shock levels and frequency bandwidths confirm performance specifications for the accelerometers that were previously unconfirmed. Results indicate the two packages are similar in response with the exception of a resonance noted in the can package that is not apparent in the flat package.

The test matrix for evaluation of the piezoresitive accelerometer for a normal or in axis input is shown in Table 2. This test matrix has been completed for the two different accelerometer configurations with the data presented in this paper and previous papers [4]. 


\section{TABLE 2 \\ TEST MATRIX FOR IN-AXIS ACCELEROMETER STUDY}

Low Amplitude High Amplitude

(up to $20,000 \mathrm{~g}$ ) (up to $200,000 \mathrm{~g}$ )

$\begin{array}{ccc}\begin{array}{c}\text { Low Frequency } \\ \text { (DC- } 10 \mathrm{kHz})\end{array} & \text { Titanium } & \text { Titanium } \\ \text { High Frequency } & \text { Beryllium } & \text { Beryllium } \\ \text { (DC-50 kHz) } & & \end{array}$

Additionally, characterization of the piezoresistive accelerometer's cross-axis sensitivity will be conducted with the titanium and beryllium Hopkinson bars. The ultimate goal is the use of beryllium for cross-axis studies because of beryllium's low Poisson ratio. Addionally, the beryllium allows shorter durations as a result of the higher wave speed. The short durations have lower stresses for any acceleration level and consequently, a smaller Poisson effect. The cross-axis tests will be performed at the same levels as the in-axis or normal tests with the exception of a maximum $g$ level limitation of $70,000 \mathrm{~g}$ for beryllium. The frequency bandwidth for these characterizations and certifications will be DC-50 $\mathrm{kHz}$ with the use of a beryllium Hopkinson bar instead of the titanium bar. A certified laser doppler vibrometer is being used to confirm the Hopkinson bar measurements for normal and cross-axis measurements. These characterizations, accomplished at the high frequencies and high shock levels, will permit better interpretation of data measured in the presence of high frequency, high shock environments.

\section{References}

1. Scott W. Walton, "New Ballistic Shock Protection Requirement for Armored Combat Vehicles," 60th Shock and Vibration Symposium, Vol. 1, November 1989.

2. Scott W. Walton, "The Significance of Shock Content Above $10 \mathrm{kHz}$ on Equipment," 63rd Shock and Vibration Symposium, Vol. 1, November 1992.

3. Scott W. Walton, "Methodology Investigation Final Report of Correlation of Component Damage to Ballistic Shock II," U.S. Army Combat Systems Activity, Aberdeen Proving Ground, MD., TECOM Report No. 7-CO-M91CSD-004, Report No. CSTA-7241.

4. V. I. Bateman, N. T. Davie, and F. A. Brown, "Characteristics of a Piezoresistive Acceleromete in Shock Environments up to 150,000 G," Proceedings of the $41^{\text {st }}$ Annual Technical Meeting, Anaheim, CA, April 30-May 5, 1995, DT\&E Volu me, pp. 217-224.
5. Akira Umeda, and Kazunaga Ueda, "Study on the Dynamic Force/Acceleration Measurements," Sensors and Actuators, A21-A23, 1990, pp. 285288.

6. K. Ueda, and A. Umeda, "Characterization of Shock Accelerometers Using Davies Bar and Strain Gages," Experimental Mechanics, September 1993, pp. 228-233.

7. V. I. Bateman, B. D. Hansche, and O. M. Solomon, "Use of a Laser Doppler Vibrometer for High Frequency Accelerometer Characterizations," Proceeedings of the 66 Shock and Vibration Symposium, Vol. II, October 30 November 3, 1995, to be published.

8. V. I. Bateman, W. B. Leisher, F. A. Brown, and N. T. Davie, "Calibration of a Hopkinson Bar With a Transfer Standard," Journal of Shock and Vibration, Vol. 1, No. 2, November-December, 1993, pp. 145-152.

9. T. C. Togami, "Hopkinson Bar Method for Direct Evaluation of High G Accelerometers," M.S. Thesis, University of New Mexico, Albuquerque, NM, August 1994.

10. R. Davies, "A Critical Study of the Hopkinson Pressure Bar," Philosophical Transactions, Series A, Royal Society of London, Vol. 240, pp. 352375, January 8, 1948.

11. H. Kolsky, Stress Waves in Solids, Oxford University Press, 1953.

12. J. Cannon and D. Rimbey, "Transient Method of Calibrating a Piezoelectric Accelerometer for the High g-level Range," American Society of Mechanical Engineers No. 71-Vibr-43, ASME Vibrations Conference and the International Design Automation Conference. September 1971, Toronto, Canada.

13. G. Brown, "Accelerometer Calibration with the Hopkinson Pressure Bar," Instrument Society of America preprint No. 49.3.63, 18th Annual ISA Conference and Exhibit, September 1963, Chicago, Illinois.

14. R. D. Sill, "Shock Calibration of Accelerometers at Amplitudes to $100,000 \mathrm{~g}$ Using Compression Waves," Proceedings of the 29th International Instrument Symposium, Albuquerque, NM, May 2-6, 1983, pp. 503-516.

15. S. D. Stearns, "Integration and Interpolation of Sampled Waveforms," SAND77-1643, Sandia National Laboratories, January 1978.

16. S. D. Stearns, Digital Signal Analysis, Hayden Book Company Inc., 1975, pp. 37-40. 


\section{DISCLAIMER}

This report was prepared as an account of work sponsored by an agency of the United States Government. Neither the United States Government nor any agency thereof, nor any of their employees, makes any warranty, express or implied, or assumes any legal liability or responsibility for the accuracy, completeness, or usefulness of any information, apparatus, product, or process disclosed, or represents that its use would not infringe privately owned rights. Reference herein to any specific commercial product, process, or service by trade name, trademark, manufacturer, or otherwise does not necessarily constitute or imply its endorsement, recommendation, or favoring by the United States Government or any agency thereof. The views and opinions of authors expressed herein do not necessarily state or reflect those of the United States Government or any agency thereof. 